\title{
INNOVATION IN INFORMATION TECHNOLOGY: THEORETICAL AND EMPIRICAL STUDY IN SMQR SECTION OF EXPORT IMPORT IN AUTOMOTIVE INDUSTRY
}

\author{
Khristian Edi Nugroho Soebandrija ${ }^{1}$, Yogi Pratama ${ }^{2}$ \\ ${ }^{1}$ Bina Nusantara University, Industrial Engineering Department, Syahdan Campus, J1. K.H. Syahdan No. 9, Palmerah, \\ Jakarta Barat 11480 Indonesia \\ ${ }^{2}$ Bina Nusantara University, Industrial Engineering Department, Syahdan Campus, JL. K.H. Syahdan No. 9, Palmerah, \\ Jakarta Barat 11480 Indonesia
}

\begin{abstract}
This paper has the objective to provide the innovation in information technology in both theoretical and empirical study. Precisely, both aspects relate to the Shortage Mispacking Quality Report (SMQR) Claims in Export and Import in Automotive Industry. This paper discusses the major aspects of Innovation, Information Technology, Performance and Competitive Advantage. Furthermore, In the empirical study of PT. Astra Honda Motor (AHM) refers to SMQR Claims, Communication Systems, Analysis and Design Systems. Briefly both aspects of the major aspects and its empirical study are discussed in the Introduction Session. Furthermore, the more detail discussion is conducted in the related aspects in other sessions of this paper, in particular in Literature Review in term classical and updated reference of current research. The increases of SMQR claim and communication problem at PT. Astra Daihatsu Motor (PT. ADM) which still using the email cause the time of claim settlement become longer and finally it causes the rejected of SMQR claim by supplier. With presence of this problem then performed to design the integrated communication system to manage the communication process of SMQR claim between PT. ADM with supplier. The systems was analyzed and designed is expected to facilitate the claim communication process so that can be run in accordance with the procedure and fulfill the target of claim settlement time and also eliminate the difficulties and problems on the previous manual communication system with the email. The design process of the system using the approach of system development life cycle method by Kendall \& Kendall (2006)which design process covers the SMQR problem communication process, judgment process by the supplier, claim process, claim payment process and claim monitoring process. After getting the appropriate system designs for managing the SMQR claim, furthermore performed the system implementation and can be seen the improvement in claim communication process and settlement time become faster and achieve the target. The conclusion in this paper comprises two major aspects. The first one refers to the conclusion in term of theory and concept. The second one refers to the conclusion in term of the empirical study of one of automotive industries in Indonesia. Both of them are expected to have contribution in current and future research of related aspects that are discussed in this paper.
\end{abstract}

\section{Keywords:}

Innovation, Information Technology, SMQR Claim, Communication Systems, Analysis and Design Systems. 


\section{Introduction}

This paper discusses the major aspects of Innovation, Information Technology, Performance and Competitive Advantage. Furthermore, In the empirical study of PT. Astra Honda Motor (AHM) refers to Shortage Mispacking Quality Report Claims (SMQR) Claims, Communication Systems, Analysis and Design Systems. Briefly both aspects of the major aspects and its empirical study are discussed in the Introduction Session. Furthermore, the more detail discussion is conducted in the related aspects in other sessions of this paper, in particular in Literature Review in term classical and updated reference of current research.

In term of Innovation, in general the preliminary discussion refers to the product and process innovation; eventually the exploratory and exploitative innovation. This paper elaborate the Innovation in term of its application in Automotive Industry as relate to Export and Import Process. The major research in Innovation that constitute the major journal reference in this paper is authored by Muscio (2010) about Product and Process Innovation, and is authored by $\mathrm{Li}$ (2010) pertaining the Exploratory and Exploitative Innovation.

In term of Information Technology, in general the preliminary discussion refers to Information Technology and its benefit in an Organization and Automotive Industry. The major research in Information Technology that constitute the major journal reference in this paper is authored by Tugas (2010) pertaining Information Technology Processes Performance, and Howard (2005) on the ICT Automotive Adoption that relates to this paper discussion.

Performance is another aspect that is important to be discussed in this paper, other than the Innovation and Information Technology. The major research in Performance that constitute the major journal reference in this paper is authored by Nandakumar (2010) pertaining Business Level Strategy and Performance. Meanwhile, Singh (2010) in his journal refers and relate the Performance with the Competitive Advantage, in particular in the area of Supply Chain as part of this paper dealing with Supply Chain of Export and Import.

Competitive advantage is elaborated in this paper, as integrated part of Innovation, Information Technology and Performance. The major research in Competitive constitutes the major book and journal reference in this paper. The book as major reference is authored by McGrath (2013) that provide insightful concept of Competitive Advantage in term of sustainable advantage versus transient advantage. The other journals refer to Competitive Advantage, authored by Almajali (2011) that relate the Competitive Advantage with IT Technology, that is suitable for the empirical study in this paper.
Meanwhile, the major journal refers to the one authored by Powell (2001) pertaining Competitive Advantage: Logical and Philosophical Consideration.

In the empirical study of PT. Astra Honda Motor (AHM), literature review refers to the concepts as indicated by Blanchard (2011), Gasperz (2011), Turban (2009) and Salvendy (2001). Precisely, the empirical study refers to current condition on the increases of production number which causes the number of part needs become higher, accordingly increases the defect found or the part condition which is not suitable with the standard of PT. Astra Daihatsu Motor (PT. ADM) and eventually increases the number of part problem that must be claimed to supplier also. Furthermore, the attention is referred to the Current Condition ( Prior 2012) and Future Condition ( Starting and Posterior End of 2012) as indicated in the following Figure 1 and 2.

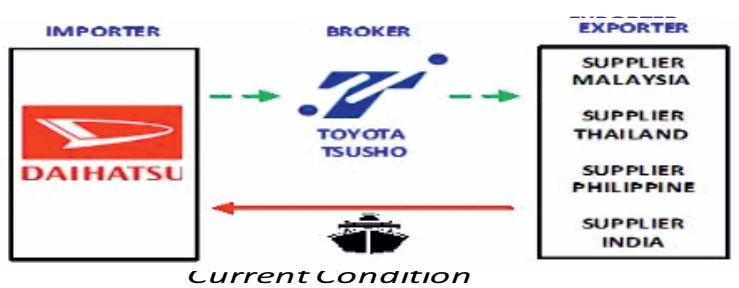

Figure 1 Current Condition of Order and Delivery

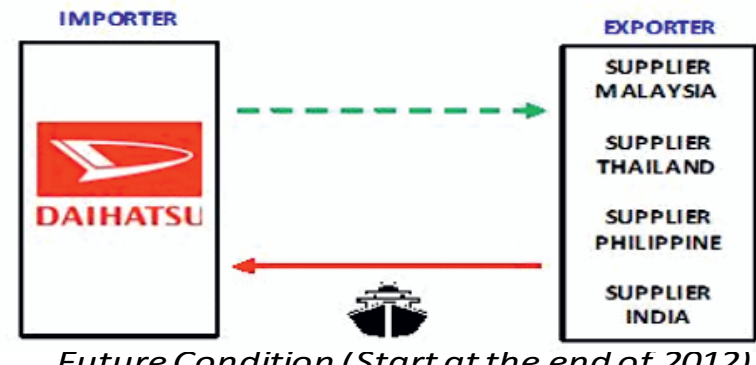

Figure 2 Future Condition of Order and Delivery

Legend:

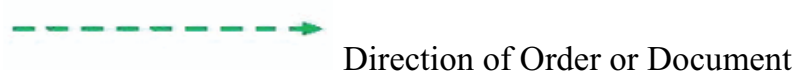

Direction of Delivery

The business scheme changes has caused the communication of SMQR claim to be conducted directly between PT. ADM with the supplier. Consequently, with that constraints in those communications process, the SMQR claim is managed well. Furthermore, the claim settlement time become longer and eventually cause the rejection of SMQR claim by the supplier. 
To avoid the communication problem such as the failure in email and the network with the various weaknesses in manual system, then it is necessary to design the integration system and to develop the PT. ADM that is expected within a system that can manage every claim. Consequently, there is no obstacle in the process and there is no new problem raises especially the problem in claim communication to the supplier. The purposes of this research is to analyze the current operational condition and find the failure and also the problem in it and then do the improvement with doing the system design, analyzing the kind of right systems to do the quality communication process and also SMQR claim process, do the system designs according to the operational process specification and according to the system needs. This system is expected to be able to delete the weaknesses in SMQR manual operation process. The step of life cycle theory of systems development methods by Kendall \& Kendall (2006), the first step of life cycle is to identify the problem, chance and purpose, in this step a system developer will formalize the problems. Then they determine the chance where the increases of using the computerized information system can be done. Then they identify the business or organization purposes if with the information system can help the business or organization reach their purposes. The second of life cycle is to determine the information requirements. In this step, will be specified the sample and raw data checking, interview, observe the behavior the decision maker and business circle and prototyping. Understand the information that required by user. The methods to determine the requirements involve the direct interaction with the user. The third of life cycle is to analyze the systems needs with data flow diagram to compose the input list, process and output business function into the structural graphic. The fourth of life cycle is to design the recommendation system. Do the entry data designs until the input data which entered into the information system is accurate. Furthermore it needs to use the forming technique and definite screen designs to certify the effectiveness the information system input. Then the fifth is developing and doing the software documentation. The sixth is testing and preserving the system and the last is implementing and evaluating the system.

\section{Literature Review}

The major research in Innovation that constitute the major journal reference in this paper is authored by Muscio (2010) about Product and Process Innovation, and is authored by Li (2010) pertaining the Exploratory and Exploitative Innovation.

Muscio (2010) emphasizes his researches through i. Lerici (1996) pertaining the Firms Innovation Needs in term of either Product and Process Innovation based upon Business Innovation Needs. ii. Istat (2005) and Peri and Zanoni (2003) in term of Proposed Technologies in term of ICT, New Materials, Machinery, Biotechnologies and Environment.
The ICT constitute the emphasized discussion in this paper of Innovation in Information Technology in Automotive Industry. Iii. De Meo (2004) through the taxonomy of Real Demand, Latent Demand and Potential Demand. The first taxonomy refers to the situation that the firm has explicit needs and is aware of the technological solutions available on the market that address its needs. The Second taxonomy refers to the situation that the firm has generic needs and is not aware of the technological solutions addressing its needs. Then, the Third taxonomy refers to the situation that The firm does not express a specific need while the general conditions of the scenario (legal, technological, market) requires it to do so.

Furthermore, Li (2010) emphasized further research about exploratory and exploitative innovation through Damanpour (1996), precisely, it is stated that An organization's innovation has a broad content: developing new products, new services, and new technologies, creating new managerial systems, new plans, and new procedures (Damanpour, 1996). According to the innovation degree and knowledge base, exploratory innovation and exploitative innovation have been classified.

In term of exploratory innovation, Li (2010) refers to several authors. Precisely, it is stated that Exploratory innovations are radical innovations and are designed to pursue the emerging probability (March, 1991).A firm's exploratory innovations offer new designs, create new market segments, develop new channels of distribution, and supply the services for emerging customers (Benner and Tushman, 2003; Danneels, 2002; Jansen et al., 2006). Exploratory innovations tend to gain and create completely new knowledge and to depart from existing knowledge (Benner and Tushman, 2002; Levinthal and March, 1993).

In term of exploitative innovation, $\mathrm{Li}$ (2010) refers to several authors as well. Precisely, it is stated that Exploitative innovations are incremental innovations and are designed to improve the existing situation (March, 1991).Afirm's exploitative innovations improve established designs, broaden existing knowledge and skills, extend and enhance the available product lines, increase the efficiency of existing distribution channels, and supply better services for existing customers (Benner and Tushman, 2003; Danneels, 2002; Jansen et al., 2006). Exploitative innovations build on existing knowledge and tend to refine, integrate, reinforce, and improve it (Benner and Tushman, 2002; Levinthal and March, 1993; Lewin et al., 1999).Also, Li (2010) mentioned and referred to other authors in term of Exploratory innovations and exploitative innovations improve firm performance in different aspects. Exploitative innovations increase efficiency in the short-term, and add te current income, while exploratory innovations increase competitive power in the long run, and add to future income (March, 1991). 
There are close relations between short- and long-term performance, efficiency and effectiveness of firms, which are reciprocal transformations. Hence, both exploratory innovations and exploitative innovations have positive effects on a firm's holistic performance.

The major research in Information Technology that constitute the major journal reference in this paper is authored by Tugas (2010) pertaining Information Technology Processes Performance, and Howard (2005) on the ICT Automotive Adoption that relates to this paper discussion.

Precisely, Tugas (2010) stated that A grounded literature on how information technology (IT) processes are being managed is imperative in an industry with an increasing reliance on IT for its strategic and operational undertakings. This study seeks to provide a comprehensive assessment of the level of IT processes performance and capability maturity.

Furthermore, Howard (2005) indicated the aspect of reveals the principle source of delay during the order fulfilment process in the automotive industry as information processing not manufacturing. This suggests that information and communication technologies (ICT) are crucial in re-shaping industry structure towards customer responsiveness and building to order. This Howard's paper reports on the findings of a longitudinal study during a critical period for the industry where firms adopting web-enabled ICT seek to increase interorganizational collaboration and gain competitive advantage over other supply chains. This paper, on SMQR of Export and Import and precisely, on Innovation in Information Technology can apply the principle that Howard indicated in his research.

The major research in Performance that constitute the major journal reference in this paper is authored by Nandakumar (2010) pertaining Business Level Strategy and Performance. Meanwhile, Singh (2010) in his journal refers and relate the Performance with the Competitive Advantage, in particular in the area of Supply Chain as part of this paper dealing with Supply Chain of Export and Import.

The major research in Competitive constitutes the major book and journal reference in this paper. The book as major reference is authored by McGrath (2013) that provide insightful concept of Competitive Advantage in term of sustainable advantage versus transient advantage. The other journals refer to Competitive Advantage, authored by Almajali (2011) that relate the Competitive Advantage with IT Technology, that is suitable for the empirical study in this paper. Meanwhile, the major journal refers to the one authored by Powell (2001) pertaining Competitive Advantage: Logical and Philosophical Consideration.

\section{Research Methodology}

The method of data collection researchers directly using stop-watches, and from the results researchers testing the adequacy of the data, the uniformity of data, SPSS test, eventually SEM, and determine the efficiency, productivity of manpower, and perform financial analysis calculations. On this quality communication system designs refers to the life cycle development system methods by Kendall \& Kendall (2006)and supported by the engineering system theory and Malcolm Baldrige with following this steps, the first is determine the theme of the study by observing the process of working on SMQR at PT. ADM. From there observations obtained theme to make improvements in the process of improving the quality of work on SMQR by system design. Then run concurrently with determination of the theme, do also study literature or library research methods. This methods is done by collecting data and information from various published sources such as books, articles, journals, references thesis and other reading materials related to the problem under study. Then formulate the problem, the purpose and scope of research the formulation of the problem described in more depth on the topic of the study is expected to be a problem that can be solved by doing this research. While the purpose of study is expected to be directly related to solving problems that are the focus in the formulation of the problem. Limiting the scope of research into issues concerning themes being studied. Then collect the historical data for problem SMQR claim to know more obstacles faced and what issues that often arise, data collection by observation on the part SMQR at PT. ADM Import Export division, Quality and Logistics, after the data is collected then testing such as the adequacy of data, validity and reliability of the data to determine whether it is able to be a good measure in this study. After all the testing is done and data collected fairly, then selajutnya depth analysis or identification of problems that exist in the data problems. Then proceed with the design of the system, beginning with the process of knowing the conditions and requirements of information systems. After that aspect is done, the system design include design documents, input and output design, process specifications, design coding and design view. Then the final stage of this design is to conduct an evaluation of the design of the system to determine whether the design of the system is feasible to be realized. Evaluation includes some important things that such systems are designed such that the information should facilitate the work process before the system is still manual and this information should support the objectives. And finally conclude that aims to determine whether this system design is made to answer the problems that were outlined in the formulation of the problem and be able to solve the problems that exist within the organization who are expected to be solved. Meanwhile, research purposes directly related to solving problems that are the focus in the formulation of the problem . Limiting the scope of research into issues concerning themes being studied. 


\section{Results and Analysis}

\section{SMQR Claim procedure}

On SMQR contained the procedure or flow that governing the reporting process and how to claim between exporters and importers. Where in the flow also set limits on the time (lead time) in conducting any process that must be adhered to by both parties either exporters or importers. The first time the process of problem discovery, and then have to make a report on the issue to the opponent for 5 business days after the problem was found, and then carried out the investigation for 10 working days and on day 10 had issued a report that contains the answer to claim acceptance or rejection of the claim . Furthermore at the same time be in issue scrap or rework claim that contains the amount of the claim amount to be paid, and as long as 10 working days later to do judgment for scrap / rework the list. And the next month on the 10th day of the billing will be done with the issuance debit notes as the final claim settlement. Target completion of all processes are in the 1 to a maximum of 3 months.

\section{Data Collection and Analysis Issues of SMQR Claim}

Historical data of SMQR problems taken from January 2010 to March 2012 for 27 months for Malaysian suppliers, by taking a number of issues of data each month, how many problems are overdue or past due deadline, the problem and the number of accepted and rejected claims received and rejected. Such data can be seen in Table 1 below.

Table 1.

Historical Claim Data for MSP Malaysia Supplier

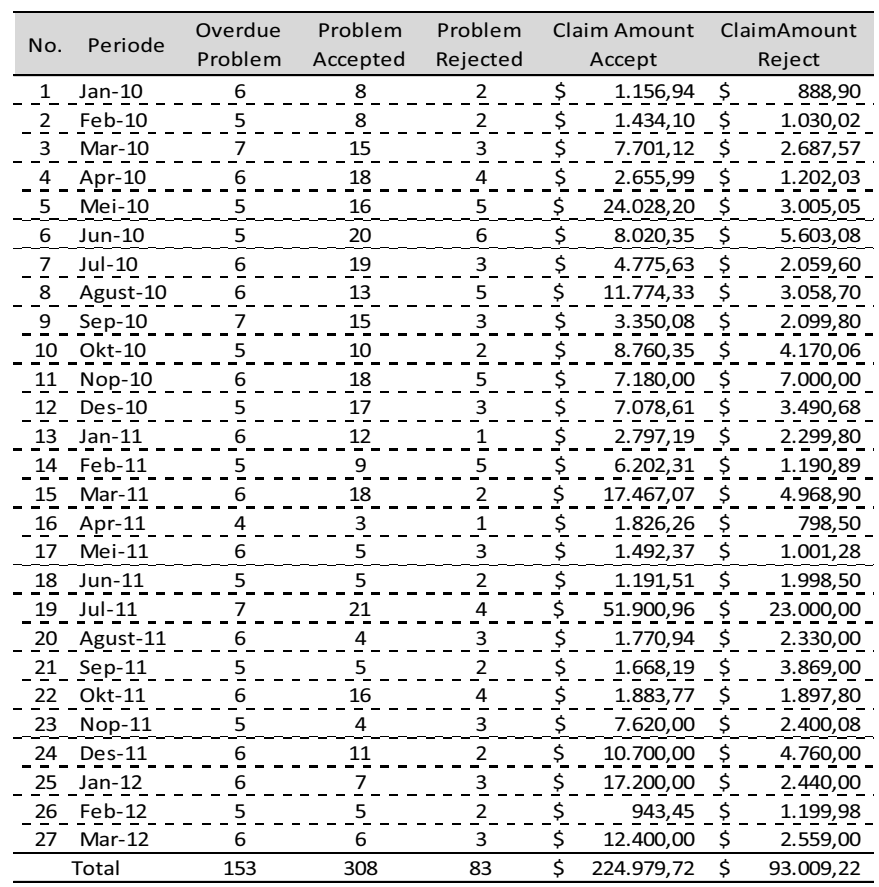

From these data and then to the data on the number of claims received and rejected amount depicted in the chart to find out and see the intensity of the rejected claim every month by observing the red bar graph in Figure 3 below.
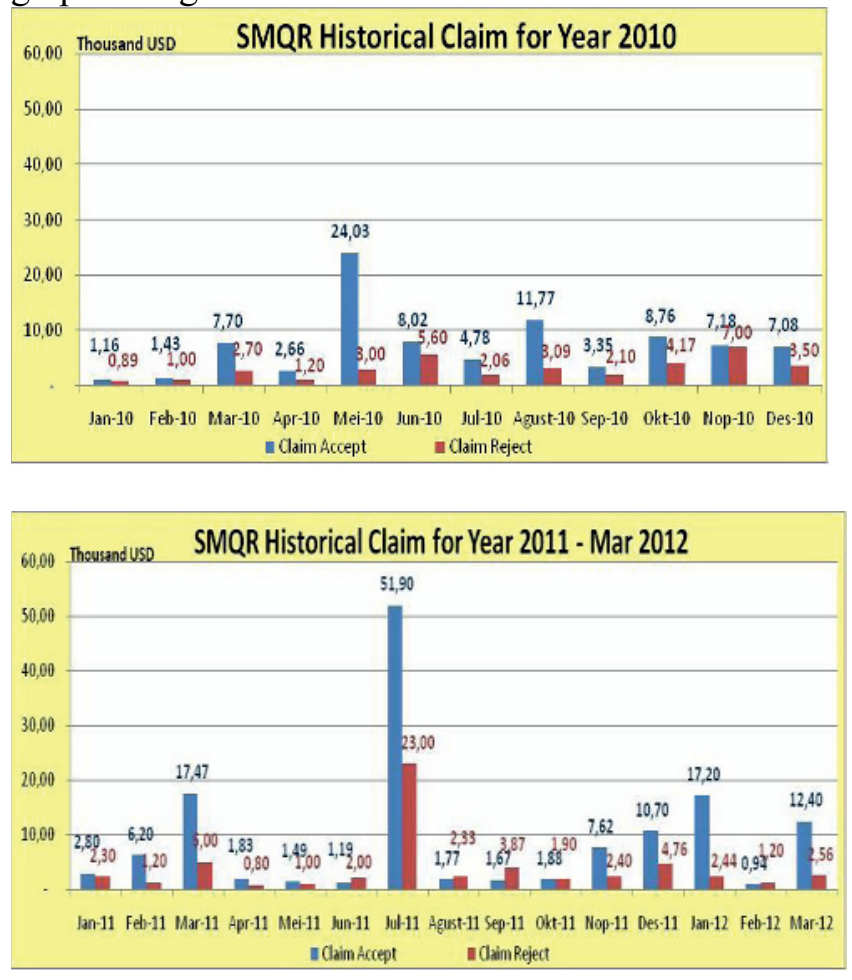

Figure 3. SMQR Historical Claim Supplier Malaysia Period January 2010 - March 2012

From the bar graph in Figure 3 it were gathered a number of claims were rejected later analysis and identification of more in-depth about why the claim was rejected. Broadly speaking, the reason for the rejection of this claim can be seen in Figure 4, which consists of a claim denial reasons that are not in the follow problem, communication problem, the data claim that doubleinput, loss of data, technical issues or result of investigation and EKLM or replacement parts.

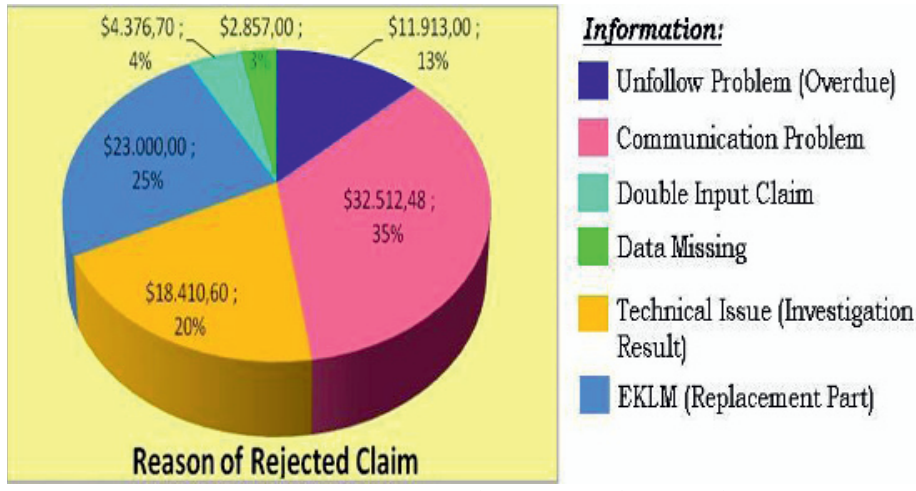

Figure 4 Reasons of Rejection Claim Supplier Malaysia period January 2010-March 2012 
From these data known one very large problems encountered in the process claim is SMQR communication problems and other issues are tried to be eliminated and overcome in the process SMQR this claim. Communication problems that arise can be analyzed from the observation in determining the terms of information, communication problems found are such problems in email, such as email damage, difficulty monitor problems, difficulties trace back history on email, kapasitasemail limitations and data loss. In addition there are several other problems such as lack of reminder systems, manual processes like approval process managers and process summary format excel.Pada problem in the data it can be seen that this claim turnaround time takes a very long time that is more than 5 months since the problem at issue. Of course the length of this process makes a lot of claims are rejected by the supplier. And from this data is also known figure in the rejected claim was for $\$ 93,009.22$ of the total claim of $\$ 317,988.94$, which means there is about $29 \%$ claim was rejected in the period. Description of the data is known issue that there are problems in the communication problem SMQR this process, and the design of this system is expected to solve these communication problems, so that the claim process is not allowed to drag on and claim the admission process will be faster.

\section{Systems Scope}

The systems scope of SMQR communication system consists of 3 components such as input, process and output. Where the input consists of a data problem and a master of master data such as part numbers, supplier data master, master calendar per-supplier working. Then the input data will be processed in a process where the process followed SMQR procedures and other processes such as the process of mapping the data into a standard format SMQR problem, the process of calculating the maturity SMQR a process, the process of communication investigative notes, making summaries problem during certain periods and processes calculations claim amount. And of the results of this processing will generate output SMQR report, an alert if past due, communication records, summaries SMQR problem and claim settlement.

\section{The Running System}

The system is still running manually using email communications, in which each process and claim reporting is done via email between exporters and importers. Here is the Use Case diagram that illustrates how the system of communication problems between exporters and importers.

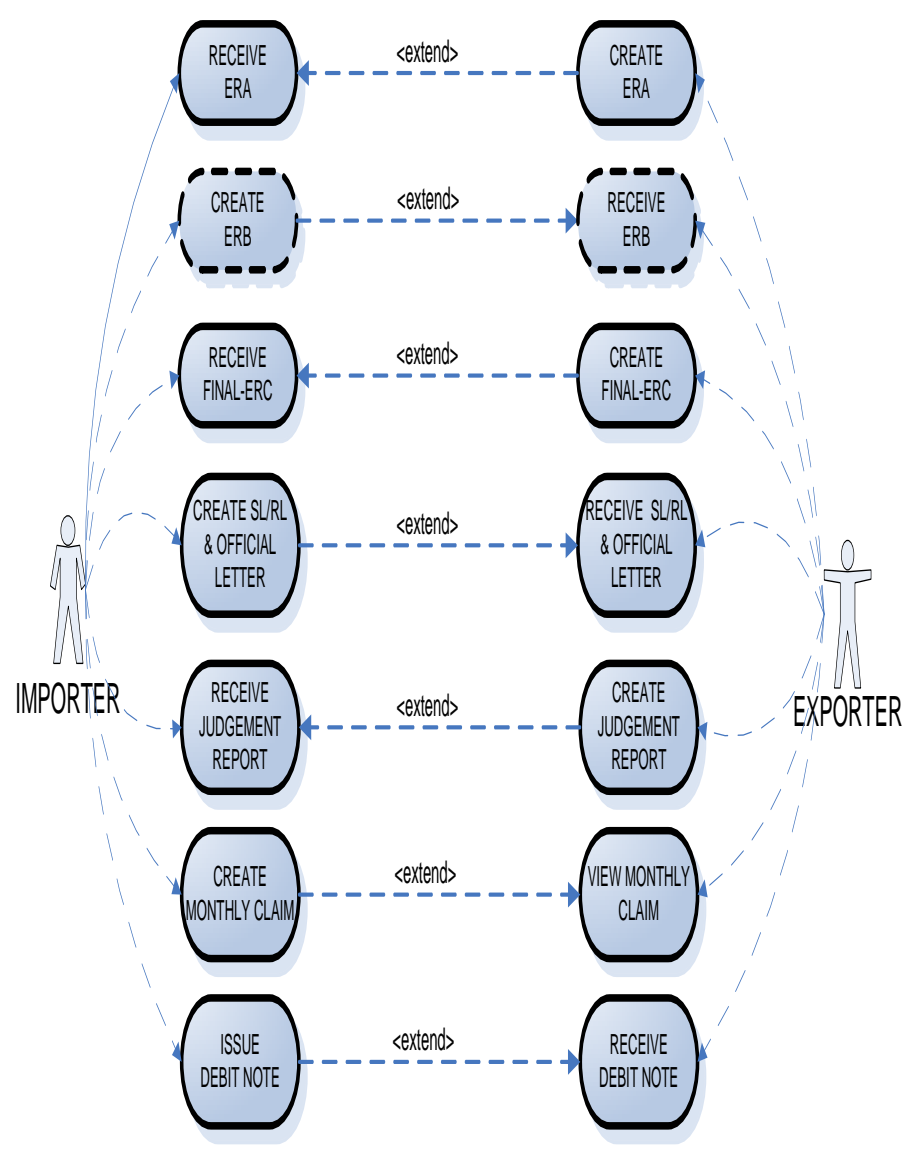

Figure 5. Use Case Diagram of SMQR Communication System Running.

The Process followed the global SMQR procedures and flow in the form of communication problems found by the importer will part sent by the exporter, information mistakes made by exporters in the form of an error in sending part so there is non-compliance with an order or other conditions such as packing damaged thus causing damage to the part and so on, the next is the approval or rejection by exporters importers would claim filed. Filing a claim until the claim is said to finally finish after such claim payment will be by exporters.

\section{The Proposed System}

The proposed system is a computerized system via the web-based internet network, all SMQR process claim as to the standard procedure performed on an integrated system with the help of the view that simplify the process of reporting the problem and claim that SMQR can be done in the process and standard reporting form. Here is a diagram that describes the context of the proposed system changes 


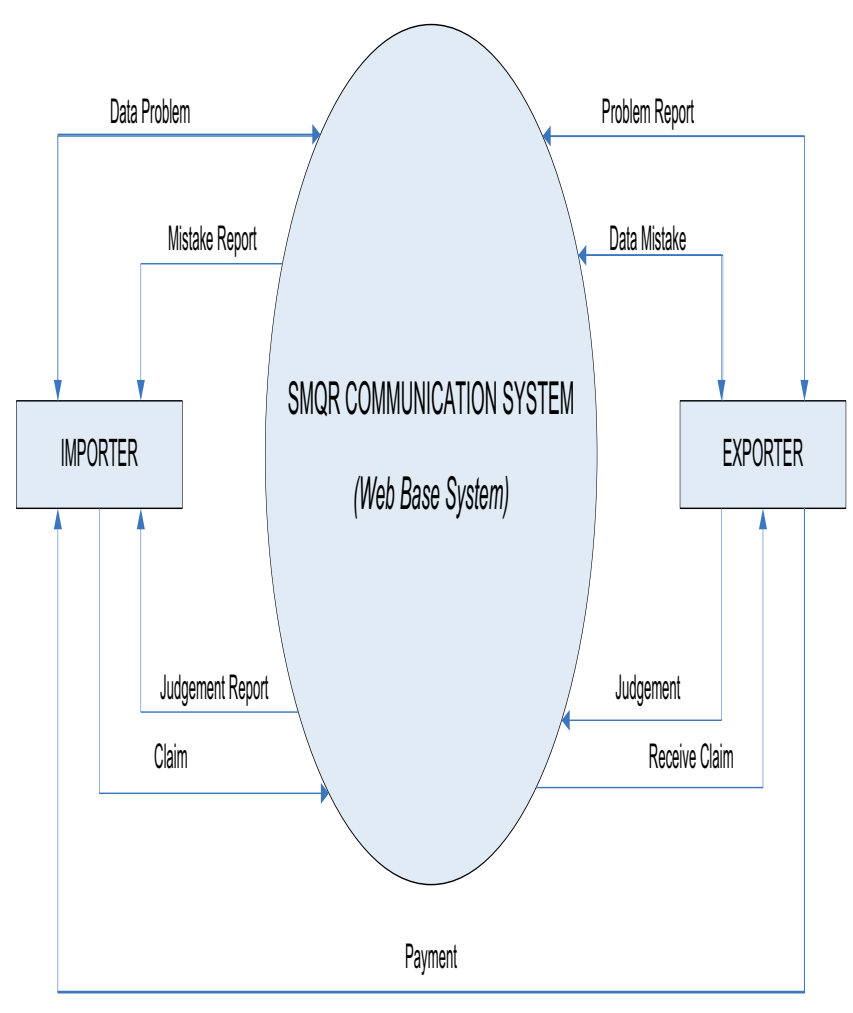

Figure 6 Diagram Context of Proposed SMQR Communication System

In the process of reporting the problem, the data entered into the system and processed in the system to report problems with standardized reporting format and can be easily accessed from the system, and then process the claim judgment was also in the system. With the ease of this system will be able to support the claim with optimal operational SMQR

\section{System Design}

System design begins with the design documents, which conducted an evaluation of the use of documents to find flaws in the operation and improvement proposals document. The researcher also did an analysis of the specification documents to obtain information what data is needed in the document, then specify the data file layout and specify the type of data. It is intended to simplify the process of data mapping issues entered into the system with the claim reporting formats as the output. Then further analysis of the specification documents to obtain information from sources such as documents, functions, frequency of data and data content globally. Having defined the types of documents and formats used, then to design the input and output process analysis and evaluation of the input of required data in a process and the output is the result of a process. Their role is to find out the source of the input data and the purpose of the output data, and also to know the format of the documents used in the input data and output data. Then after doing the design input and output is then performed an analysis of the specification process to be performed on this system. This process specification contains a description of each function or process that has been described previously in the data flow diagram. On the specifics of the process will be explained about the input, output, input the data store, the data store and an explanation of the logic output process. This is a process specification processes are carried out in accordance with the reporting and claim procedures such issue SMQR ERA report, issue ERB report, Interim-ERC, PRR, issueERC Final, scrap / rework list, monthly claims and debit notes. After completion of the analysis process continued with the design specifications coding, the system takes a unique code that will be used as the characteristics of each process and also to distinguish one claim with another claim. To meet these needs then the design encoding which consists of the design code ER / SMQR No. which consisted of two conditions, namely if the problem at issue by PT. ADM and if the problem in issue by the parties outside the PT. ADM. Then do also design code exporter, importer code, plant code, code division / department and control code. Development of code ER / SMQR No. used to distinguish one problem with another problem that in issue in this system, in the determination of this unique code based on year and month of the discovery of the problem, then the state comes supplier, supplier code, code and serial number of the originator importers claim that all these aspects are combined. And the last part in this scheme is to perform the design view, the structure of the menu system designed display is divided into two divisions based on the function menu of the user who uses the system, the user as the user as an importer or exporter. The division is based on the menu structure of the task or function of the importer or exporter in accordance with global SMQR flow to support any process that is the responsibility of the exporter or importer. The design of this display will simplify the process of system development by programmers because it will give you an idea of how to run the system, in addition to the good design of the display will also support when this system is used in making SMQR claim, because the display is appropriate and will facilitate systematic work claim Here you are. Serelah all completed the design data and document this collected design into a user requirement which will be used by the system developer or programmer to create this system.

\section{System Test}

After designing and development of this system completed then the observation is conducted against trials process of SMQR claim who has been running during one month of namely month of December 2012 for MSP supplier Malaysia with using communication system quality this. On period one month this was a transitional period from process SMQR claim manual become computerized. The trial is conducted against supplier Malaysia because the number of supplier who managed only 2 supplier, is more a little compared to supplier in the State another. Besides it was supplier in Malaysia is a sister company from PT. ADM so that given the ease in the process of socialization until implementations sistem.There are 16 problem as shown in Table 2 the following table. 
Table 2 Data of SMQR Problem for Period December 2012 (After Improvement)

\begin{tabular}{|c|c|c|c|c|c|c|c|c|c|c|}
\hline No & ER/SQMR No. & Problem Issue & Final-ERC & SL/RL Judgeme & Judgement & Days & & Amount & & unt $/ 1000$ \\
\hline 1 & 12ZMYAL2001 & 6-Dec-2012 & 19-Dec-12 & 27-Dec-12 & A & 14 & $\$$ & 477,76 & $\$$ & 0 \\
\hline 2 & 002 & . & 2000 & & & 14 & $\$$ & $1.892,29$ & $\$$ & 101 \\
\hline 3 & 12ZMYAQ2004 & 9-De & 26-De & & & 18 & $\$$ & 320,42 & 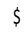 & \\
\hline 4 & ZZMYA & De & 20-Dec-12 & & & 14 & & 402,42 & & \\
\hline 5 & 12ZMYAQ2006 & & & & & 14 & ? & 400 & $?$ & \\
\hline 6 & 2ZMYAQ2007 & 7-Dec- & 26-Dec-12 & & & 25 & & 230,00 & $\$$ & \\
\hline 7 & & & & & & 16 & & 25589 & & \\
\hline & 12ZMYAQ2009 & & 7.-Jan-13 & & & 15 & 3 & 320,42 & & \\
\hline 9 & & & 7.Jan & & & 15 & 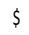 & 0,42 & & \\
\hline & $12 \mathrm{ZM}$ & & 7-Jan-13 & $18 \mathrm{-J}$ & & 15 & & 320,42 & & 0 \\
\hline & & & Jan-13 & 18--Jan & & & & $3.204,16$ & & \\
\hline
\end{tabular}

Having seen the data then analyzed against the rejection ratio of the data SMQR claim after improvement are managed using the system. Comparing the rejection ratio of the data before the improvement. Shows that the rejection ratio of the period 2010 to March 2012 was approximately $29 \%$ of these results obtained from the total claim rejected divided by the total of the entire claim. Meanwhile, if we look at the variation in each month are the smallest rejection ratio is $11 \%$ in May 2010 and most of it is 70\% in September 2011. Whereas if the percentage rejection ratio on averaged data, the result is rejection ratio of approximately $36 \%$ compared to every monthly problem.If in December 2012 after using a quality communication system that is designed as shown in Table 2, are known to reject the total claim is $\$ 230$ and the total claim amounted to $\$ 108,197.54$ so rejection ratio for the month of December 2012 was at $0.21 \%$, so it can be seen a decline in numbers of SMQR claim rejection ratio. This result occurs because the number of problems in very few reject the claim of the month and with a relatively small amount compared to the total claim amount. In addition it also made observations on the completion time of the claim in December 2012, from observational data to test communication systems for the management SMQR claim to Malaysia can be seen from Table 2 that the completion time of a claim can be made within two months, in which time varies investigation for approximately 16 working days. So that the targets set in the global SMQR claim settlement process flow that carried a maximum of 3 months to be fulfilled after the improvement of communication systems.

\section{CONCLUSION}

The conclusion in this paper comprise two major aspects. The first one refers to the conclusion in term of theory and concept. The second one refers to the conclusion in term of the empirical study of one of automotive industries in Indonesia. Both Concept and Theory, and empirical study are put in conclusion to ensure the balance between those two aspects, for the purpose of full swing development in this research from both aspects.
First, for the conclusion that refers to the theory and concept, it is indispensable to refer to several authors and their researches, which are i. Muscio (2010) about Product and Process Innovation, ii. Li (2010) pertaining the Exploratory and Exploitative Innovation. iii. Tugas (2010) pertaining Information Technology Processes Performance. iv. Nandakumar (2010) pertaining Business Level Strategy and Performance. v. Singh (2010) in his journal refers and relate the Performance with the Competitive Advantage, in particular in the area of Supply Chain as part of this paper dealing with Supply Chain of Export and Import. vi. McGrath (2013) that provide insightful concept of Competitive Advantage in term of sustainable advantage versus transient advantage. Vii. Almajali (2011) that relate the Competitive Advantage with IT Technology, that is suitable for the empirical study in this paper. Viii. Powell (2001) pertaining Competitive Advantage: Logical and Philosophical Consideration.

Second, for the conclusion that refer to the empirical study; it is concluded that after conducting the analysis and design of communication systems claim SMQR in PT. Astra Daihatsu Motor there are many positive aspects of system design are made primarily in operational ease SMQR claim of the discovery process problems, communication problems and the problems of judgment until payment claim.Beberapa conclusions of the analysis and design of systems that have been done such that the designed system is a new system which is a shift from manual to computerized system SMQR and web-based methods in designing the system development life cycle followed by Kendall \& Kendall (2006) and supported by methods of system engineering and Malcolm Baldrige. The designed system is a system used to support the activities of a process claim on SMQR adapted to existing procedures. With this system can improve claims turnaround time and to meet the target completion time of a claim that is a maximum of 3 months. Proven on trial in December 2012 for MSP Malaysia supplier SMQR claim that has been managing the system can resolve the claim within 2 months and reached 100\% settlement. These systems can reduce the rejection rate SMQR claim, by conducting tests on the data problem in December 2012 which has been managed using the system. Seen that the original total rejection ratio is $29 \%$ with an average per month varies between 36\% (period Jan 2010 - Mar 2012) can go down to $0.21 \%$ (Month December 2012). As for some suggestions in this study are as follows to maintain the appropriate claim turnaround time target of 1 to a maximum of 3 months it is necessary to control and monitor the process status function communication system SMQR follow in order to know the progress of settlement and claim to know the warning if there is a process SMQR claim of passing lead time, so the time does not drag on claim settlement .For keep claim revenues each month to keep it high is to continue to maintain and manage the communication process claim on the system properly and obeying predetermined lead time. 


\section{REFERENCES}

1. Almajali, D.A, Dahalin, M.Z. (2011). Factors influencing IT-Business Strategic Alignment and Sustainable Competitive Advantage: A Structural Equation Modelling Approach.IBIMA Publishing.

2. Benner, M.J. and Tushman, M.L. (2002), "Process management and technological innovation: a longitudinal study of the photography and paint industries", Administration Science Quarterly, 47, p. 676-706.

3. Benner, M.J. and Tushman, M.L. (2003), "Exploitation, exploration, and process management: the productivity dilemma revisited", Academy of Management Review, 28, p. 238-56.

4. Blanchard, Benjamin S. \& Fabrycky, Wolter J. (2011). Systems Engineering and Analysis. United States of America: Pearson

5. Damanpour, F. (1996), “Organizational complexity and innovation: developing and testing multiple contingency models", Management Science, 42 No. 5, p. 693-716.

6. Danneels, E. (2002), "The dynamics of product innovation and firm competences", Strategic Management Journal, 23, p. 1095-121.

7. De Meo, E. (2004), "Industria alimentare e sistema innovativo in Puglia', Politica agricola internazionale, p. 1-2.

8. Gaspersz, V. \& Fontana, A. (2011). Malcolm Baldrige Criteria for Performance Excellence. Bogor: Vinchristo Publication

9. Howard, M. (2005). Collaboration and the '3DayCar': a study of automotive ICT adoption. Journal of Information Technology, 20, p. 245-258.

10. Istat (2005), Statistiche sulla Ricerca Scientifica, Istat, Roma.

11. Jansen, J.J.P., van den Bosch, F.A.J. and Volberda, H.W. (2006), "Exploratory innovation, exploitative innovation, and performance: effects of organizational antecedents and environmental moderators", Management Science, 52 (11), p. 166174.

12. Kendall, K. E., \& Kendall, J. E. (2006). Analisis dan Perancangan Sistem. Jakarta: Indeks

13. Lerici, C.R. (1996), “L'innovazione nella moderna tecnologia alimentare', Atti V Convegno Nazionale ANDID, Positive Press Verona 1997, Rimini.
14. Levinthal, D.A. and March, J.G. (1993), "The myopia of learning", Strategic Management Journal, 14, p. 95-112.

15. Lewin, A.Y., Long, C.P. and Caroll, T.N. (1999), "The coevolution of new organizational forms", Organization Science, 10, p. 535-50.

16. Li, Y., Zhou, N., Si, Y. (2010).

Exploratory innovation, exploitative innovation, and performance: Influence of business strategies and environment. Nankai Business Review International 1 No. 3, p. 297-316

17. March, J.G. (1991), "Exploration and exploitation in organizational learning", Organization Science, 2, p. $71-87$

18. McGrath, R.M (2013). The End of Competitive Advantage. Harvard Business Review.

19. Muscio, A., Nardone, G., Dottore, A (2010) Understanding demand for innovation in the food industry. Measuring Business Excellence. 14(10), p. $35-48$

20. Nandakumar, M.K, Ghobadian, A., O'Regan, N., (2010). Business-level strategy and performance: The moderating effects of environment and structure. Management Decision 48(6),p. 907-939.

21. Peri, C. and Zanoni, B. (2003), Manuale di Tecnologie Alimentari, 1, Cusl, Milano.

22. Salvendy, G. (2001). Handbook of Industrial Engineering: Technology and Operations Management, John Wiley \& Sons, Inc.

23. Singh, R., Sandhu, H.S, Metri, B.A., Kaur, R.(2010). Relating Organized Retail Supply Chain Management Practices, Competitive Advantage, and Organizational Performance. VISION-The Journal of Business Perspective 14(3), p. 174-190.

24. Tugas, F.C (2010). Assessing the level of information technology processes performance and capability maturity in the Philippine food, beverage and tobacco (FBT) Industry using the COBIT Framework. Academy of Information and Management Sciences Journal, 13(1).

25. Turban, E. (2009). Introduction to Information Systems : Enabling and Transformasi Business, John Wiley \& Sons, Inc 